\title{
ESTILOS E DIMENSÕES DA LIDERANÇA: INICIATIVA E INVESTIGAÇÃO NO COTIDIANO DO TRABALHO DE ENFERMAGEM HOSPITALAR ${ }^{1}$ \\ STYLES AND DIMENSIONS OF LEADERSHIP: INITIATIVE AND INVESTIGATION IN HOSPITAL NURSING DAILY WORK \\ ESTILOS Y DIMENSIONES DEL LIDERAZGO: INICIATIVA E INVESTIGACIÓN EN EL COTIDIANO DEL TRABAJO DE LA ENFERMERÍA HOSPITALARIA
}

\author{
Iraci dos Santos ${ }^{2}$, Carolina Bittencourt Castro ${ }^{3}$
}

\begin{abstract}
${ }^{1}$ Recorte da Dissertação Dimensões da Liderança: Um estudo de características individuais e profissionais do enfermeiro na instituição hospitalar defendida no Programa de Pós-Graduação em Enfermagem da Universidade do Estado do Rio de Janeiro em 2007.

${ }^{2}$ Doutora em Enfermagem. Professor Titular de Pesquisa em Enfermagem. Professora do Programa de Pós-Graduação em Enfermagem da Universidade do Estado do Rio de Janeiro. Orientadora da dissertação. Rio de Janeiro, Brasil.

${ }^{3}$ Mestre em Enfermagem. Enfermeira Chefe de Unidade de Clínica Médica do Hospital de Ipanema. Rio de Janeiro, Brasil.
\end{abstract}

PALAVRAS-CHAVE: Liderança. Administração hospitalar. Enfermagem.

KEYWORDS: Leadership. Hospital management. Nursing.

PALABRAS CLAVE: Liderazgo. Administración hospitalaria. Enfermería.

RESUMO: Considerando que as dimensões de liderança dos enfermeiros condiciona seu estilo gerencial, delimitou-se como problema: quais são os estilos dominante e subdominante de liderança do enfermeiro no exercício de atividades gerenciais segundo sua autopercepção? Tem-se como objetivo identificar o estilo Grid adotado por enfermeiros, segundo as dimensões de liderança, iniciativa e investigação, no cotidiano do trabalho de enfermagem hospitalar. Trata-se de pesquisa descritiva-quantitativa, realizada em hospital do Rio de Janeiro. Foram entrevistados 66 enfermeiros de junho a julho de 2007. Constatouse na dimensão iniciativa como estilos: 5.5 dominante e 9.9 subdominante. Na dimensão investigação, o estilo 9.9 é dominante e o 1.1, subdominante. Conclui-se que o estilo 1.1, como subdominante do enfermeiro, revela que os sujeitos tendem a se acomodar. Portanto, idealizam um estilo de liderança 5.5 (Homem Organizacional) compatível com às necessidades da equipe de enfermagem e com os objetivos da instituição hospitalar.

ABSTRACT: Considering that leadership dimensions of nurses condition our management style, the following was delimited as a problem: which are the dominant and subdominant styles of nursing leadership in the exercise of management activities, according to his self-perception? The objective of this study was to identify the Grid style adopted by nurses, according to leadership, initiative, and research dimensions within the daily work of hospital nursing. This is a quantitative, descriptive study which was carried out in a hospital in Rio de Janeiro, Brazil. From June to July, 2007, 66 nurses were interviewed. In the initiative dimension style, 5.5 were noticed to be dominant and 9.9, subdominant. In the investigation dimension styles, 9.9 is dominant and 1.1, subdominant. We conclude that style 1.1, as the nurse's subdominant, reveals that the subjects tend not to care, thus idealizing leadership 5.5 (Organizational Man) compatible with nursing team's needs and institution aims.

RESUMEN: Considerando que las dimensiones de liderazgo de los enfermeros condicionan su estilo de gerencia, en el presente estudio se delimitó como problema: ¿cuáles son los estilos dominantes y subdominantes del liderazgo del enfermero en el ejercicio de actividades de gerencia según su propia percepción? El objetivo fue identificar el estilo Grid que los enfermeros adoptan, según las dimensiones de liderazgo, iniciativa e investigación, en el cotidiano del trabajo de enfermería hospitalaria. Se trata de una investigación descriptiva y cuantitativa, realizada en el hospital de Rio de Janeiro, Brasil, siendo entrevistados 66 enfermeros, en el período de junio a julio de 2007. En la dimensión iniciativa se pudo constatar como estilos: 5.5 dominante y 9.9 subdominante. En la dimensión investigación, el 9.9 es dominante y el 1.1 es subdominante. Se concluye que el estilo 1.1, como subdominante del enfermero, revela que los sujetos tienden a acomodarse, idealizando un estilo de liderazgo 5.5 (Hombre Organizacional) según las necesidades del equipo de enfermería y los objetivos de la institución

Iraci dos Santos

Endereço: Rua General Roca, 572, ap. 901

20521-070 - Tijuca, Rio de Janeiro, RJ, Brasil

E-mail: iraci.s@terra.com.br
Artigo original: Pesquisa Recebido em: 15 de abril de 2008 Aprovação final: 10 de outubro de 2008 


\section{INTRODUÇÃO}

O questionamento sobre liderança é fundamental para a enfermagem desenvolver ações relacionadas à competência e habilidade do enfermeiro líder em estabelecer comunicação e ações diretivas visando a participação das pessoas no alcance das metas desejadas pelo grupo de trabalho e a organização. ${ }^{1}$ A integração entre o papel de liderança e o exercício da função de gerência pelo enfermeiro é desejada por influenciar o cumprimento de normas e rotinas, a previsão e provisão de recursos materiais e ambientais e contribuir para a eficiência da gerência do enfermeiro. ${ }^{2} \mathrm{~A}$ liderança contribui para que o envolvimento, satisfação e motivação transformem a atividade profissional dos membros da equipe de enfermagem numa atividade prazerosa, pois a jornada de trabalho e a remuneração são fatores relevantes para o descontentamento dos profissionais.

Portanto, o comportamento do líder gera um reflexo no desempenho do grupo de trabalho, já que esta equipe se espelha no modelo que acredita ou percebe como necessário para a execução de suas práticas de atendimento à clientela. Ao observar o comportamento desta equipe, em contrapartida, é possível inferir o estilo de liderança exercido pelo enfermeiro gerente, pois o cotidiano de trabalho da enfermagem determina o momento certo de o líder adotar comportamentos e atitudes diversas a fim de envolver e comprometer sua equipe. Assim, para melhor entender a liderança como um fenômeno de grupo estudou-se a percepção de profissionais que a exercem, inclusive como exigência do cargo que ocupam.

Nesse sentido, buscou-se reconhecer as particularidades de seus comportamentos em situações do cotidiano do trabalho gerencial junto aos seus liderados. Vislumbrando as nuanças próprias dos enfermeiros que exercem função de gerência, delimitou-se como problema: quais são os estilos dominante e subdominante de liderança do enfermeiro no exercício de atividades gerenciais segundo sua autopercepção? Espera-se que os estilos de liderança sejam a principal expressão da sua capacidade de atingir resultados esperados pelas equipes de trabalho disciplinar, interdisciplinar, multiprofissional e pela instituição hospitalar. Para responder essa questão, formulou-se o objetivo: identificar o estilo Grid adotado por enfermeiros, segundo as dimensões de liderança iniciativa e investigação, no cotidiano do trabalho de enfermagem hospitalar.
Este trabalho se justifica através da seguinte premissa: conhecendo estilos de liderança do enfermeiro, pode-se contribuir para a reflexão acerca da liderança em enfermagem na perspectiva de encontrar aspectos relevantes para a construção de uma nova prática profissional na administração do processo de trabalho e do cuidar em saúde e enfermagem. Além disso, percebe-se a existência de poucos estudos envolvendo estilos Grid Gerencial, ${ }^{3}$ dimensões de liderança, inclusive esses estilos de dominante e subdominante, conforme se destaca a seguir.

Estudos sobre a utilização da Teoria Grid Gerencial revelaram que o estilo 9,9, segundo a avaliação dos atendentes, auxiliares e técnicos de enfermagem, é totalmente desejável em relação à liderança do enfermeiro, enquanto os estilos 5,5 e 1,9 são desejáveis e os 9.1 e 1.1 são totalmente indesejáveis. ${ }^{4}$ Referente aos estilos Grid, a revisão bibliográfica permitiu descrever a mesma seqüência de estilos percebidos pelo enfermeiro como desejáveis e indesejáveis, em estudos anteriores. ${ }^{5}$ Comparando os estilos de liderança idealizados pelos enfermeiros em duas instituições, constatouse que se mantiveram os resultados conhecidos, confirmando-se os achados anteriores, segundo a autopercepção do líder sobre seu estilo de liderança. ${ }^{6}$ Do mesmo modo, os achados de trabalho realizado em 2006 reforçam a mesma percepção dos enfermeiros quanto aos seus estilos de liderança 9,9, seguido por 5,5 e 9,1, e destacando a rejeição dos estilos 1,9 e 1,1. ${ }^{7}$ Entretanto, utilizando o método sociopoético para identificar formas de liderança segundo a dimensão imaginativa da equipe de enfermagem, observou-se, em 2007, comportamentos gerenciais compatíveis aos estilos 9,1, 9,9,5,5 e 1,1, sem contudo haver ordem de preferência dos estilos de liderança. ${ }^{7}$

Assim, esta pesquisa, visando aprofundar a análise dos resultados obtidos sobre os estilos gerenciais Grid, na literatura consultada, retoma a discussão referente à identificação dos enfermeiros líderes, constante ao longo dos anos de 1990 a 2006. A relevância do estudo se aplica à medida que, conhecendo mais sobre liderança, se obtém mais êxito no relacionamento com a equipe, e a partir daí a resolução de problemas assistenciais na área da saúde e enfermagem ocorrerá de forma mais rápida, direcionada e precisa. As equipes disciplinar e a multiprofissional, como um todo, dispondo de um setor organizado e trabalhando com um líder que privilegie a gerência de equipe, se sentirão mais satisfeitas e motivadas no desenvolvimento de suas atividades. 
Desse modo, os clientes serão os principais beneficiados, pois receberão um cuidado eficiente, com qualidade e condizente com sua dignidade humana. Pretende-se, ainda, elevar e ampliar as discussões sobre liderança nas instituições de ensino de enfermagem durante a graduação e nas instituições de saúde, principalmente com os líderes de enfermagem. Acredita-se, também, que, com a nova política de humanização do Sistema Único de Saúde e o Programa Nacional de Humanização, a liderança ganhará mais força e será fundamental para o alcance dos objetivos institucionais, se a considerarmos como a habilidade de trabalhar entusiasticamente, junto às pessoas, visando atingir os objetivos identificados como sendo para o bem comum. ${ }^{7}$

\section{MARCO TEÓRICO-METODOLÓGICO}

Utilizou-se como marco referencial a Teoria Grid Gerencial, considerando que se encontra na trajetória estrutural - profissional gerentes e líderes de enfermagem com diferentes estilos de liderança, sendo que essa teoria descreve mais de 81 estilos a partir dos cinco principais característicos da cultura gerencial das organizações. Essa teoria foi elaborada por Robert Blake e Jane Mouton, ${ }^{3}$ na década de 20, a partir dos resultados encontrados nos estudos sobre liderança, onde se definiu duas dimensões básicas: orientada para produção e orientada para pessoas, denominadas de: 9,1 (Gerência com autoridade / obediência); 1,9 (Gerência de clube campestre); 1,1 (Gerência empobrecida); 5,5 (Gerência do homem organizacional); 9,9 (Gerência de equipe). O número 1 significa orientação mínima para pessoas e produção; o número 5 significa orientação média para pessoas e produção e o número 9 orientação máxima, para pessoas e para produção. Intui-se que a orientação máxima para produção revela inclinação quanto ao apoio das teorias clássica e funcionalista da administração, que privilegia a produtividade. Enquanto a orientação máxima para pessoas reflete uma aderência às de relações humanas e comportamentais. Nesta pesquisa, o referencial teórico é utilizado para explicitar os estilos gerenciais Grid denominados pelos autores como "puros".

O gerente 9,1 necessita de poder, controle e domínio sobre as pessoas. Receia o fracasso e, se ele ocorre, atribui a culpa aos outros. Para ele a eficácia operacional decorre da organização das condições de trabalho, com grau mínimo de interferência do elemento humano. Na sua visão, produção e pessoas são dimensões inconciliáveis. É constante sua preocupação com o trabalho, devendo-se obter produção custe o que custar. As reações dos subordinados frente ao tipo de conduta 9,1 são variadas. Alguns se enquadram e se sujeitam à dominação, uma vez que consideram corretas as ordens dadas. Outros, sob tensão, cumprem as determinações discordando das mesmas. Outros, rotineiramente, executam o que lhes foi atribuído, apenas para cumprir sua incumbência, sem se envolver e adotando uma atitude de neutralidade e indiferença. ${ }^{3}$

O estilo 1,9 toma decisões que ajudam e apóiam as pessoas, cria um relacionamento amistoso, atmosfera agradável e ritmo confortável de trabalho. Tem medo da rejeição e precisa ser apreciado pelos seus subordinados. Sua reação baseia-se nas incertezas criadas por ele mesmo e não nas propriedades objetivas da situação. Em seu empenho para evitar a rejeição, mostra-se atencioso, bondoso e, sobretudo, solícito no atendimento às pessoas. Ele prefere investir nas pessoas, pois acredita que se constituem no recurso mais importante da organização. As reações dos subordinados diversificam desde o sentimento de segurança decorrente de um ambiente amigável até a percepção de abafamento e frustração diante de um ambiente sem desafios. Nessa abordagem, deve ser feito todo o possível para que as pessoas se sintam satisfeitas com as condições de trabalho e com o próprio chefe. ${ }^{3}$

O gerente 1,1 investe o mínimo necessário para a execução do trabalho, com o propósito de manter a sua participação na organização. Emocionalmente, o gerente 1,1 já se demitiu e se retirou para a indiferença, entretanto deseja manter-se no sistema tendo em vista a sua sobrevivência. Despreocupa-se com a produção e com as pessoas, o que significa fazer apenas o suficiente para preservar o seu emprego e contar tempo de serviço, mas sem dar uma verdadeira contribuição a seus colegas ou à organização. Ele espera pouco e oferece pouco. O grau de sua indiferença e não-envolvimento coincide com o mínimo que as pessoas estão dispostas a suportar. Comumente justifica sua apatia e improdutividade atribuindo a culpa em algo fora dele. Os subordinados sob a gerência deste estilo, reagem de formas variadas: protestam, reagem contra, derivam para uma reação 1,1 ou deixam a organização. ${ }^{3}$

O equilíbrio entre a necessidade de realizar o trabalho, metas de produção e a preocupação em manter a disposição de ânimo e moral das pessoas são características do gerente estilo 5,5, o qual busca um desempenho satisfatório da organização. Sua motivação positiva é participar, causar boa impressão, obter aceitação de seu grupo, ser sociável, 
angariar um extenso círculo de relacionamentos, demonstrar status. Teme causar má impressão, tornar-se marginalizado pelo grupo, cair no ridículo, sentir-se impopular e isolado. Prefere ser popular desenvolvendo maneiras agradáveis nos seus relacionamentos, adotando as opiniões em voga e rejeitando o que os outros não aprovam. Raramente as reações dos subordinados são hostis ou agressivas face ao estilo 5,5. Sob essa orientação, alguns subordinados adotam o estilo 5,5, passam a pensar e a atuar da mesma forma como são dirigidos, pautando-se pelo status quo, ou seja, pelas normas e tradições da organização. ${ }^{3}$

A posição 9,9 é caracterizada pela gerência em equipe, procurando alcançar resultados excelentes através da participação, envolvimento e comprometimento. Esse estilo de liderança anseia contribuir para o sucesso da organização e compromete-se a envolver todas as pessoas nesta missão, promovendo abertura, espontaneidade, confiança, respeito, responsabilidade compartilhada e competência. Sua maior apreensão é o desapontamento e a frustração decorrentes de algum fracasso ou de alguma contribuição medíocre, entretanto tal ocorrência não lhe debilita a persistência. Ao planejar as atividades, envolve as pessoas que dispõem de dados ou que têm responsabilidade pelos resultados, reunindo-as para que examinem todo o panorama, formulam juntas um modelo global que integrem os diversos projetos, obtêm das pessoas suas reações e idéias e a seguir estabelece com elas metas e programas flexíveis. Com essas mesmas pessoas o gerente organiza o trabalho, determinando as responsabilidades individuais, os procedimentos e as normas básicas. No exercício do controle, juntamente com os responsáveis, critica durante a execução de cada projeto e promove uma avaliação final com o intuito de aprender para o futuro, demonstrando reconhecimento em termos de equipe e destacando as contribuições individuais mais notáveis. ${ }^{3}$

\section{Sobre estilos dominantes e subdominantes e dimensões da liderança}

Observando na literatura a existência de poucos estudos envolvendo estilos Grid Gerencial, nas modalidades de dominante e subdominante, optouse por investigá-las acreditando que os enfermeiros geralmente adotam estilos alternativos quando se encontram em circunstâncias críticas. O entendimento sobre a importância desses estilos permite ao líder compreender o momento ideal para apresentar um determinado comportamento. Os estilos domi- nantes e subdominantes surgem como alternativas de resolução de determinado conflito ou situação indesejáveis, na qual o líder dispõe de habilidades de compreender e refletir sobre a melhor maneira de alcançar o resultado desejável.

Na teoria Grid, enfatiza-se que os estilos empregados pelos gerentes, durante o trabalho, podem ser complexos. O estilo dominante ou mais típico é o mais importante para entender como uma pessoa exerce a gerência, porém, nem sempre ele será o primeiro a ser usado em uma determinada situação, citando-se como exemplo: um gerente poderá iniciar uma reunião de modo cordial e descontraído, mas utilizar rapidamente uma abordagem 9,1 assim que passarem a tratar do trabalho. Mesmo que o início cordial e descontraído seja do tipo 1,9, a abordagem 9,1 é dominante..$^{3: 17}$

Para compreender as abordagens dominantes e subdominantes, é necessário observar durante um tempo os vários comportamentos e as situações envolvidas. Alguns gerentes mudam mais de comportamento que outros. Exemplo: um líder sob orientação 1,9 prefere ceder e submeter-se, mas talvez se torne inflexível e exigente $(9,1)$ se a pressão aumentar demasiadamente. Um líder que tente manter o controle e a autoridade segundo a orientação 9,1, mas encontre resistência contínua por parte de seus subordinados, poderá mudar para uma base de trabalho de equipe segundo a orientação 9,9, tendo em vista a solução em conjunto de problema. ${ }^{3: 17}$ A variedade de combinações de estilos dominantes e subdominantes é que faz de cada gerente uma pessoa extremamente singular.

As dimensões da liderança são: a iniciativa, a investigação, o posicionamento, a solução de conflitos, a tomada de decisão e a crítica. Dependendo do comportamento do líder, podemos caracterizar essas dimensões e definir os estilos de liderança. ${ }^{3}$ A iniciativa se configura no esforço exercido para a realização de uma atividade específica onde se busca iniciar o que não existia antes, encerrar o que ocorria ou desviar a direção ou o tipo de esforço. Cabe ao líder tomar uma iniciativa ou desistir dela, mesmo quando os outros esperam que ele o faça. A investigação permite ao líder acesso a fatos e dados oferecidos por pessoas e outras fontes de informação. A qualidade da informação dependerá dos esforços do líder. Um líder com capacidades de exigência diminuída poderá ignorar a necessidade de investigação. ${ }^{3}$

O posicionamento caracteriza-se pela capacidade do líder de defender seus pontos de vista. Pode correr de o líder ter convicções bem definidas, 
mas temer expô-las, ao passo que pode deixar de assumir uma posição por possuir conviç̧ões pouco consistentes. ${ }^{3}$ O líder pode abraçar certa posição para fazer oposição ou para vencer alguém. A solução de conflito ocorre quando diversos pontos de vista se expressam de forma positiva ou negativa, isto é, o conflito se apresenta como criativo e construtivo ou como perturbador e destrutivo. ${ }^{3}$ Merece respeito e consideração o líder que consegue resolver o conflito de forma a se chegar ao entendimento recíproco. A incapacidade de enfrentar e resolver um conflito de modo construtivo leva à falta de respeito e à hostilidade do grupo.

A tomada de decisão é aplicada ao desempenho do líder. As decisões podem ser tomadas individualmente, somente o líder responde pela decisão final, ou delegadas, onde o trabalho em equipe reúne os recursos disponíveis para influenciar a tomada de decisão ou sua execução. A crítica é o processo de afastamento ou interrupção de uma atividade com o objetivo de propor possibilidades alternativas para melhorar o desempenho, prever e evitar quaisquer atividades que causem conseqüências adversas. As experiências profissionais se confluem através de feedback, com o objetivo de aperfeiçoar atividades futuras e tornar o trabalho mais eficaz. ${ }^{3}$

\section{METODOLOGIA}

Foi implementado o método descritivo e a técnica de auto-relato, em entrevista individual com os sujeitos, feita pela pesquisadora. ${ }^{8} \mathrm{~A}$ coleta de dados foi realizada no ambiente natural onde os enfermeiros desenvolvem suas atividades de liderança, qual seja, a instituição hospitalar. Para tanto elaborou-se um formulário estruturado que foi respondido pelos componentes da população alvo do estudo sobre o tema liderança. Na escolha do método e técnica de pesquisa, considerou-se as seguintes dimensões dos delineamentos de pesquisa quantitativa: modalidade de comparação de grupos, cujo delineamento de pesquisa é entre sujeitos, ${ }^{8}$ pois serão investigados os estilos adotados por diversos enfermeiros que atuam em diferentes situações de liderança.

\section{Campo da pesquisa, sujeitos do estudo e variáveis do estudo}

O campo da pesquisa é um hospital geral universitário, com atenção voltada para a pesquisa e que contribui para o ensino de enfermagem através do programa de internato e residência em enfermagem. Caracteriza-se por ser de alta complexidade e de grande porte, vinculado à rede pública de saúde e situado no município do Rio de Janeiro-RJ. A população é constituída por enfermeiros, considerando-se como critério de inclusão: exercício da atividade de liderança na qualidade de coordenador geral de enfermagem, coordenadores de serviços, supervisores e chefes de unidades operacionais de atendimento ao cliente. Mediante levantamento do quantitativo desses funcionários, realizado na Coordenadoria de Enfermagem do hospital citado, constatou-se a existência de 77 enfermeiros desempenhando as funções delimitadas nesta pesquisa. Como critério de exclusão, considerou-se: não assinar o Termo de Consentimento Livre e Esclarecido (TCLE) para participar da pesquisa, estar de férias ou licença, preencher incorretamente ou não completar o preenchimento do instrumento de coleta de dados e/ ou não devolvê-lo. Obedecendo aos requisitos éticos de pesquisa em seres humanos (Resolução do Conselho Nacional de Saúde No 196/96 e 251/97), após parecer positivo da Comissão Examinadora, o projeto de dissertação foi encaminhado ao Comitê de Ética em Pesquisa do Hospital Universitário Pedro Ernesto (HUPE) da Universidade do Estado do Rio de Janeiro, obtendo aprovação em dezembro de 2006 - Protocolo No 1653-CEP/HUPE.

Foram selecionadas como variáveis do estudo as percepções dos enfermeiros sobre os cinco estilos gerenciais Grid em situações do cotidiano de trabalho relacionadas às cinco dimensões de liderança. Recorda-se que o delineamento da pesquisa é naturalista porque os dados foram coletados no próprio ambiente de trabalho dos sujeitos. Para compor o Instrumento de Coleta de Dados (ICD), foram criadas questões delimitando-se situações a partir do cotidiano do trabalho gerencial do enfermeiro, adaptadas de um questionário que associou as dimensões da liderança já descritas. ${ }^{9}$

\section{Estratégia de produção de dados}

Após aprovação do Comitê de Ética em Pesquisa, os sujeitos selecionados foram convidados pessoalmente e aceitaram por terem entendido o objetivo, vantagem e desvantagens da pesquisa. Eles assinaram o TCLE e autorizaram a divulgação de suas respostas, desde que respeitado seu anonimato. A produção de dados através do ICD realizou-se de junho a julho de 2007, contando-se com 66 enfermeiros que atendiam aos critérios de inclusão já definidos. O ICD é um formulário de múltipla escolha contendo variáveis que são analisadas a partir de perguntas que suscitam seis 
opções, cada uma delas correspondente a um estilo gerencial Grid $(9,9 ; 5,5 ; 9,1 ; 1,9 ; 1,1)$. Considerando a possibilidade de o respondente não se identificar com nenhum desses estilos, foi incluída a sexta opção "outro". Nela, os sujeitos têm a oportunidade de expressar seus próprios estilos de liderança. Todas as opções foram enumeradas em ordem de preferência de um a cinco, se inexistir a descrição de opção "outro"; ou de um a seis devendo a opção "outro" ser descrita pelo informante. Portanto, foi oferecido um total de seis perguntas representando as dimensões do comportamento de liderança, a saber: iniciativa, investigação, solução de conflitos, posicionamento, decisão e crítica.

As situações abordadas referem-se ao cotidiano do processo de trabalho de enfermagem tais como: planejamento do cuidado de enfermagem, implementação da terapêutica, controle/coordenação da continuidade das atividades de enfermagem, caracterizada pela passagem de plantão, supervisão do desempenho técnico do profissional de enfermagem e avaliação/crítica quanto à qualidade do atendimento ao cliente pela equipe de enfermagem. Alerta-se que essas questões são de origem fictícia, correspondem aos estilos de liderança e foram extraídas de duas fontes: as dimensões iniciativa, investigação, solução de conflitos e crítica; ${ }^{9}$ as dimensões posicionamento e tomada de decisão. ${ }^{3}$ A justificativa da utilização das duas fontes refere-se ao fato de as opções formuladas por um determinado pesquisador ${ }^{9}$ estarem mais próximas da realidade do trabalho de enfermagem. Releva-se que não foi realizado teste piloto do ICD por ter sido este já validado em pesquisa cujos resultados foram publicados. ${ }^{9}$

A obrigatoriedade em ordenar todas as opções referentes aos estilos de liderança foi apontada por alguns sujeitos da pesquisa, porém, quando orientados quanto à necessidade de enumerar todas as questões, e que isto representaria uma ordem de preferência e não necessariamente as etapas de suas ações, houve concordância no preenchimento completo do instrumento. Reforça-se que a opção "outro" foi analisada de acordo com a descrição dos respondentes. Para o tratamento dos dados, utilizou-se a estatística simples descritiva, optandose, neste recorte de dissertação, por apresentar apenas a freqüência percentual dos dados coletados referentes aos estilos e dimensões de liderança.

\section{RESULTADOS E DISCUSSÃO}

\section{Estilos gerenciais Grid autopercebidos por enfermeiros líderes}

Analisando a Tabela 1, identifica-se que os resultados apontam, segundo a percepção dos enfermeiros, a predominância do estilo 5,5 - Gerência do homem organizacional, em dimensões expressivas para o exercício da liderança: iniciativa, posicionamento e solução de conflito. Seguem-se os estilos 9,9 - Gerência de equipe e 1,9 - Gerência do clube campestre. Enquanto os estilos 9,1 - Gerência com autoridade e obediência e 1,1 - Gerência empobrecida foram pouco percebidos nas dimensões da liderança crítica e investigação, respectivamente. Vê-se, portanto, que tais resultados são diferentes do encontrado na revisão de literatura referente à liderança de enfermagem do período de 1990 a 2006. $\cdot^{3-6}$ Correlacionando os estilos gerenciais puros dominantes e subdominantes $(9.9,9.1,5.5,1.9,1.1)$ e o descrito (opção outro) pelo enfermeiro líder, sujeito de pesquisa às dimensões do comportamento (iniciativa, investigação, solução de conflitos, posicionamento, tomada de decisão e emoções).

Tabela 1 - Estilos Grid gerencial autopercebidos pelo enfermeiro segundo as dimensões da liderança. Rio de Janeiro-RJ, 2007

\begin{tabular}{|c|c|c|c|c|c|c|c|c|c|c|}
\hline \multirow{3}{*}{$\begin{array}{l}\text { Dimensões } \\
\text { da liderança }\end{array}$} & \multicolumn{10}{|c|}{ Estilos } \\
\hline & \multicolumn{5}{|c|}{ Dominante } & \multicolumn{5}{|c|}{ Subdominante } \\
\hline & 9.9 & 9.1 & 5.5 & 1.9 & 1.1 & 9.9 & 9.1 & 5.5 & 1.9 & 1.1 \\
\hline Iniciativa & & & $54,55 \%$ & & & $34,85 \%$ & & & & \\
\hline Investigação & $78,79 \%$ & & & & & & & & & $25,76 \%$ \\
\hline Solução de conflitos & & & & $37,88 \%$ & & & & $46,97 \%$ & & \\
\hline Posicionamento & & & $43,94 \%$ & & & & & $50,00 \%$ & & \\
\hline Tomada de decisão & $60,61 \%$ & & & & & & & & $40,91 \%$ & \\
\hline Crítica & & $66,67 \%$ & & & & & & & $42,42 \%$ & \\
\hline
\end{tabular}

Texto Contexto Enferm, Florianópolis, 2008 Out-Dez; 17(4): 734-42. 
Releva-se que, neste trabalho, por se tratar de um recorte ampliado de Dissertação de mestrado, são apresentados apenas os resultados relativos às dimensões de liderança iniciativa e investigação enfocando as questões que deram origem às respostas dos sujeitos de pesquisa. Justifica-se a escolha dessas dimensões principalmente por terem alcançado os escores mais altos tanto o estilo predominante 5,5 na modalidade subdominante, quanto o estilo 9,9, na modalidade dominante. A dimensão iniciativa geralmente é associada a uma qualidade humana esperada para o exercício da liderança, enquanto espera-se do líder gerente de equipe que desenvolva seu trabalho tendo como premissa a dimensão investigação.

\section{Dimensão iniciativa e estilos Grid}

$\mathrm{Na}$ dimensão iniciativa interroga-se o comportamento do líder frente à questão: existe uma prescrição de enfermagem para fazer hidratação da pele a cada mudança de decúbito nos clientes acamados? A maioria dos enfermeiros líderes se percebe como estilo dominante 5,5 - Gerência do homem organizacional. Entretanto, adotam como comportamento o estilo subdominante o equivalente ao 9,9 - Gerência de equipe. Destacando-se as opções relacionadas aos estilos 5,5 (Eu explico como e porque o trabalho deve ser feito e de vez em quando verifico seu cumprimento) e 9,9 (Mantenho-me ciente do andamento do trabalho, se necessário, dou assistência ajudando a remover as barreiras do caminho); infere-se que, pelo fato de o enfermeiro condicionar-se às normas institucionais, surpreendentemente ele se percebe no seu comportamento real. A adoção do estilo 9,9 como estilo subdominante revela o que ele deseja ser no exercício de sua gerência.

Constata-se que a situação do status quo define o campo de ação, se o objetivo é executar as operações de modo ordenado e aceitável. Nesse caso, o esforço é mantido em ritmo igual e o exercício da iniciativa é limitado (estilo 5,5$){ }^{3}$ Porém, espera-se que haja esforço em se concentrar energia no exercício da iniciativa espontânea e entusiástica, para despertar o envolvimento e o comprometimento do grupo de trabalho (estilo $9,9) .{ }^{3}$ Destaca-se, ainda, nas descrições dos sujeitos da pesquisa, referentes à opção "outro", conforme se exemplifica nas características das Gerências.

Empobrecida - 1,1: Avalio o doente conforme a prescrição, expondo a ele o procedimento e pedindo sua ajuda, se for possível (Marisa); Acredito que os pro- fissionais fazem da melhor maneira, pois dou abertura para orientação e troca de idéias (Fátima);

Homem organizacional - 5,5: Eu explico a importância e porque temos que fazer e verifico regularmente (Cristiano). Lembra-se que esse gerente segue o prescrito nas normas institucionais e não toma iniciativa para atender situações específicas, suscitando o aparecimento de liderança informal.

\section{Dimensão investigação e estilos Grid}

O erro na administração da terapêutica medicamentosa foi o condicionador da atitude do líder referente à dimensão investigação. Verificou-se no cômputo geral dos estilos dominantes que a maioria de enfermeiros líderes se percebem como estilo 9,9 - Discuto os erros com as pessoas nele envolvidas a fim de diagnosticar as causas que o sustentam. Portanto, essa dimensão no estilo 9,9 é abrangente e profunda, assegurando a avaliação analítica de todas as bases, possibilitando o entendimento total de problemas reais, sendo importante o levantamento de fatos e dados, e obtenção, por indagação, de provas tanto contraditórias quanto de apoio. ${ }^{3}$

Enquanto no estilo subdominante $(25,76 \%)$ os enfermeiros se percebem com o comportamento do estilo 1,1 - Argumento que a equipe deve ter preparo suficiente para não cometer erros. Referente a esta evidência, o sujeito que adota este estilo prefere saber menos sobre o assunto e alegar ignorância. Considera que é melhor permanecer dentro de uma concha e não olhar nem para a direita e nem para a esquerda. ${ }^{3}$ Observa-se uma distância muito grande entre os dois estilos. Ao avaliar o estilo dominante descrito pelos sujeitos, constatou-se que nessa dimensão os lideres se preocupam com a segurança e as causas que podem levar os clientes ao risco. Essa preocupação é também compartilhada com a equipe médica. Os enfermeiros, ao descreverem seu pensamento sobre a opção de estilo "outro", não consideram apenas a posição evitar erros, mas a de corrigi-los, a partir do diálogo com seus responsáveis alertando sobre as conseqüências, inclusive administrativas para a repetição de erros.

Vários autores alertam para a responsabilidade de os gerentes de enfermagem apoiarem sua equipe no desenvolvimento da administração da terapêutica medicamentosa, pois esta é uma atividade que demanda grande parte do tempo de trabalho dos membros dessa equipe. O conhecimento sobre farmacologia permite ao enfermeiro 
avaliar conseqüência e interações medicamentosas. Em trabalho sobre análise do planejamento de horários de aprazamento de medicamentos em unidade de terapia intensiva cardiológica, foi identificado que os anti-hipertensivos são os mais prescritos..$^{10}$ Alerta-se, desse fato, o cuidado dos gerentes na prevenção de iatrogenias por interações medicamentosas indevidas, sendo fundamental para os enfermeiros aprofundarem seus conhecimentos visando proteger os clientes dos efeitos adversos procedentes dos erros na terapêutica medicamentosa. Ainda na descrição da opção "outro" estilo, os enfermeiros revelam sua preocupação em comunicar o erro ao médico solicitando sua ajuda para resolução do problema pois esse é o prescritor universal, sendo portanto, imprescindível o diálogo com este profissional.

\section{CONSIDERAÇÕES FINAIS}

Compreender os estilos e dimensões da liderança desde a Teoria Grid Gerencial para verificar quais são os estilos dominante e subdominante do enfermeiro justifica-se porque a literatura do período de 1993 a 2006 revela serem os estilos 9,9 e 5,5 os preferencialmente percebidos como adotados por esse profissional. Neste caso, reflete-se que seu desempenho gerencial nem sempre tem sido apontado como compatível com esses estilos. ${ }^{11}$

Respondendo ao problema formulado neste trabalho identificou-se, ao associá-los às dimensões da liderança, que: na dimensão iniciativa, o estilo Grid dominante se configura na Gerência do homem organizacional $(5,5)$, o qual pretende manter o status quo da instituição. Assim, alertase para a tendência desse estilo para a rotinização predominantemente instituída nas instituições burocráticas. A impessoalidade nas atitudes desse líder revela sua submissão ou vinculação mais acentuada às normas preestabelecidas. Quanto ao estilo subdominante, percebido como 9.9 (Gerência de equipe), lembra-se que sua característica é incentivar a participação do grupo para o alcance dos objetivos organizacionais e profissionais.

Considerando-se a dimensão investigação, o estilo dominante refere-se ao estilo 9,9 - Gerência de equipe, cujo comportamento administrativo privilegia a avaliação da situação, a fim de entender, junto ao grupo, os problemas que a geraram. O estilo subdominante 1,1 - Gerência empobrecida, menos percebido pelos enfermeiros, revela que quando se é impossível identificar os reais problemas, os sujeitos tendem a se acomodar.
Ao considerar o estilo 9,9 identificado como próprio dos enfermeiros, segundo sua autopercepção, ressalta-se que este fato configura uma tentativa real de idealização de um estilo que contemple as necessidades pessoais da equipe de enfermagem e do enfermeiro líder, associada aos objetivos da instituição em prol da satisfação de ambas as partes. No entanto, o estilo 5,5 predomina, como sendo adotado pelos enfermeiros do campo da pesquisa. Recorda-se que estudiosos, dessa área do conhecimento, contemporizam este fato salientando que a liderança na enfermagem vem sendo exercida na profissão de maneira cristalizada, idealizada, envolta por um caráter mítico, contribuindo para a manutenção do status quo e para uma certa alienação dos trabalhadores da área. ${ }^{12: 67}$ Existe, portanto, uma tendência à burocratização do processo de trabalho da enfermagem, considerando que os enfermeiros cada vez mais assumem atribuições que extrapolam suas competências e por conseguinte os afastam da assistência direta ao cliente e ainda mais de seus liderados. . $^{1,72-13}$

Assim, reforça-se que a discussão sobre as dimensões de liderança e estilos gerenciais é necessária na medida em que se busca o desenvolvimento de habilidades e competências que preparem os enfermeiros para assumir um papel de destaque no desenvolvimento de seu trabalho.

Considera-se, ainda, que a inclusão de variáveis do estudo contemplando aspectos problematizados do cotidiano do trabalho em grupo, associados às dimensões da liderança, favoreceu uma percepção mais aproximada do estilo real do enfermeiro líder. Diante dos resultados obtidos, acredita-se haver necessidade de qualificação gerencial visando preparar os enfermeiros para assumirem cargos que exigem a integração das funções de chefia e liderança. Confirma-se, portanto, que o cuidar em saúde e enfermagem exige uma formação profissional que privilegie não só o preparo técnico-científico da área da saúde e enfermagem, mas, também, a consciência da utilização de qualidades humanas. Isso porque o trabalho do enfermeiro líder, nas instituições de saúde, visa ao alcance de objetivos comuns à instituição, às equipes de trabalho e ao cliente. Neste caso, a liderança na enfermagem, como um fenômeno de grupo, será entendida pelo líder como um desafio no sentido de compartilhar idéias, esforços e recursos para satisfação de clientes e profissionais. 


\section{REFERÊNCIAS}

1. Castro CB. Dimensões da Liderança: Um estudo de características individuais e profissionais do enfermeiro na instituição hospitalar [dissertação]. Rio de Janeiro (RJ): Universidade Estadual do Rio de Janeiro. Programa de Pós-Graduação em Enfermagem; 2007.

2. Marquis BL, Huston CJ. Administração e liderança em Enfermagem: teoria e aplicação. $2^{a}$ ed. Porto Alegre (RS): Artes Médicas; 1999.

3. Blake R, Mouton J. O Grid gerencial. São Paulo (SP): Pioneira; 2000.

4. Trevizan MA. A liderança do enfermeiro: o ideal e o real no contexto hospitalar. São Paulo (SP): Sarvier; 1993.

5. Melo MRA. O Grid gerencial: uma análise descritiva na área da enfermagem. Esc Anna Nery Rev Enferm. 2004 Ago; 8(2):275-8.

6. Trevizan MA, Higa EFR. Os estilos de liderança idealizados pelos enfermeiros. Rev Latino-am Enferm. 2005 Jan-Fev; 13(1):59-64.

7. Santos I, Oliveira SRM, Castro CB. Gerência do processo de trabalho em enfermagem: liderança da enfermeira em unidades hospitalares. Texto Contexto Enferm. 2006 Jul-Set; 15(3):393-400.
8. Polit B, Beck CT, Hungler D. Fundamentos de Pesquisa em Enfermagem. Porto Alegre (RS): Artmed; 2004.

9. Santos, I. Estilos gerenciais dos enfermeiros na área de recuperação da saúde. In: Gauthier JHM, Cabral IE, Santos I, Tavares, CMM. Pesquisa em enfermagem: novas metodologias aplicadas. Rio de Janeiro (RJ): Guanabara Koogan; 1997.

10. Fontenele RE, Araujo TL. Análise de planejamento dos horários de administração de medicamentos em unidade de terapia Intensiva cardiológica. Rev Enferm UERJ 2006 Jul-Set; 14(3):325-32.

11. Dourado TG, Santos I. dos. Activities of nurse- direct and indirect care to hospitalized client: a descriptive study. Online Braz J Nurs. 2007 Jan-Mar; 6(1):40-3.

12. Rozendo CA, Gomes ELR. Liderança na enfermagem brasileira: aproximando-se de sua desmistificação. Revista Latino-am Enfermagem. 1998 Dez; 6(4):67-76.

13. Santos I dos, Castro CB, Corrêa LA, Dourado TG. Estilos de gerência: percepção da enfermeira quanto aos estilos gerenciais na administração do processo de trabalho da assistência de enfermagem. In: Anais do $13^{\circ}$ Pesquisando em enfermagem. Rio de Janeiro, UFRJ/EEAN, 2006. p.24-32. 